\title{
ATELLLIE
}

\section{Lazer em Altamira-PA e as tranformações após a construção da Usina Hidrelétrica de Belo Monte}

\author{
Leisure in Altamira-PA and the transformations after the \\ construction of Belo Monte Hydroelectric Power Plant
}

\author{
Ocio en Altamira-PA y los cambios después de la \\ construcción de la central hidroeléctrica Belo Monte
}

\author{
Francivaldo José da Conceição Mendes \\ Univerisidade Federal do Pará \\ francivaldo.edfisica@gmail.com
}
César Augusto Martins de Sousa
Univerisidade Federal do Pará
cesar@ufpa.br

José Queiroz de Miranda Neto

Univerisidade Federal do Pará

geoneto@msn.com

\begin{abstract}
Resumo
Esta pesquisa investigou as manifestações do lazer na cidade de Altamira-PA, considerando as transformações urbanas advindas da implementação da Usina Hidrelétrica "Belo Monte" (UHBM). De maneira geral, descreveu-se as principais práticas de lazer existentes na cidade de Altamira, considerando a relevância da implementação da UHBM como evento indutor de um considerável reordenamento na lógica da (re)produção dos espaços de lazer. As entrevistas abertas e a observação participante constituíram-se em estratégias metodológicas dessa pesquisa, na medida em que possibilitaram uma melhor compreensão da realidade do lazer de Altamira. Os resultados evidenciaram um forte processo de (re)definição dos espaços de lazer, caracterizados pela ação de agentes, instituições, Estado, e dos sujeitos residentes na cidade. A realidade emergente evidencia uma nova dinâmica dos espaços e das mútiplas práticas de lazer no advento da UHBM. Tem destaque nesse cenário, a emergência de novos arranjos na "territorialidade do lazer", caracterizados pelas novas formas estabelecidas pelos sujeitos, destacando-se o aumento dos espaços privados de lazer em comparação aos públicos.
\end{abstract}

Palavras-Chave: Lazer, Hidrelétrica Belo Monte, Altamira-PA. 


\begin{abstract}
This present research investigated the leisure manifestations in the city of AltamiraPA, considering the urban transformations resulting from the implementation of the Belo Monte Hydroelectric Power Plant (BMHPP). In general, the main leisure practices in the city of Altamira were described, considering the relevance of the BMHPP implementation as an inducing event of a considerable reordering in the (re) production of leisure spaces. The first interviews and the participant observation constituted in methodological strategies of this research, in what they made possible a better understanding of the reality of the leisure of Altamira. The results evidenced a strong process of (re) definition of leisure spaces, characterized by agents, institutions, State, and residents living in the city. The emerging reality shows new dynamics of spaces and multiple leisure practices in the advent of UHBM. In this scenario, the emergence of new arrangements in the "leisure territoriality", characterized by the new forms established by the subjects, stands out the increase of the private spaces of leisure in comparison to the public ones.
\end{abstract}

Keywords: Leisure, Altamira-PA, Collective Urban Resettlements.

\title{
Resumen
}

Esta investigación investigó las manifestaciones del ocio en la ciudad de AltamiraPA, considerando las transformaciones urbanas resultantes de la implementación de la Central Hidroeléctrica Belo Monte (UHBM). En general, se describieron las principales prácticas de ocio en la ciudad de Altamira, considerando la relevancia de la implementación de UHBM como un evento que induce una considerable reorganización en la lógica de la (re) producción de espacios de ocio. Las entrevistas abiertas y la observación participante fueron estrategias metodológicas de esta investigación, ya que permitieron una mejor comprensión de la realidad de ocio de Altamira. Los resultados evidenciaron un fuerte proceso de (re) definición de espacios de ocio, caracterizado por la acción de agentes, instituciones, el estado y los residentes de la ciudad. La realidad emergente evidencia una nueva dinámica de espacios y las múltiples prácticas de ocio en el advenimiento de UHBM. Destacar en este escenario, la aparición de nuevos arreglos en la "territorialidad del ocio", caracterizados por las nuevas formas establecidas por los sujetos, destacando el aumento de los espacios de ocio privados en comparación con los públicos.

Palabras clave: Ocio, hidroeléctrica Belo Monte, Altamira-PA.

\section{Introdução}

Esta pesquisa desenvolveu-se no município de Altamira-PA, cidade localizada na mesoregião sudoeste ${ }^{1}$ do Pará com uma população estimada em 2017, de 111.435 habitantes (IBGE, 2017). A constituição histórica da cidade tem sido marcada por ciclos, estágios decisivos para a configuração da cidade enquanto polo regional, destacando-se aqueles ocorridos nas últimas quatro décadas, primordiais na alteração demográfica e estrutural da cidade.

\footnotetext{
${ }^{1}$ A Mesoregião sudoeste congrega 14 municípios e está dividida em duas microrregiões, Itaituba e Altamira. Esta última está diretamente ligada a influência territorial, política e econômica de Altamira articulando oito municípios ao longo da BR 230 (Rodovia Transamazônica) e do rio Xingu (Médio Xingu): Altamira, Anapú, Brasil Novo, Medicilândia, Pacajá, Senador José Porfírio, Uruará e Vitória do Xingu (IBGE, 2017).
} 
Umbuzeiro e Umbuzeiro (2012) sintetizam a constituição histórica de Altamira em 05 (cinco) ciclos. O primero deles é carcaterizado pelas missões jesuíticas, considerada pelos autores como sendo a pré-história de Altamira. Essas missões iniciaram-se ainda no século XVII e finalizaram-se no século XIX. Além desse ciclo, os autores destacam outros quatro: o $1^{\circ}$ ciclo da borracha, o $2^{\circ}$ ciclo da borracha, a constução da Rodovia Transamazônica e, por fim, o quinto ciclo, marcado pelo início da construção da Usina Hidrelétrica "Belo Monte" (UHBM), atualmente em processo de finalização por parte da Empresa Norte Energia S.A (NESA), responspavel pela construção e operação da usina por um período de 35 anos .

Considerando a realidade apresentada, este trabalho estruturou-se a partir do que se considera uma problemática a investigar, que é a inserção de mais um projeto de infraestrutura na região, neste caso a UHBM. Assim, problematizou-se o seguinte: a construção da UHBM constitui-se num elemento fundamental para a reconfiguração das práticas de lazer no espaço urbano de Altamira?

No bojo dessa problemática, considera-se que há uma estrutura ineficiente de lazer público na cidade de Altamira e nos Reassentamentos Urbanos Coletivos (RUCs), somada a um reordenamento nas/das práticas de lazer na cidade como uma considerável elevação dos espaços privados de lazer.

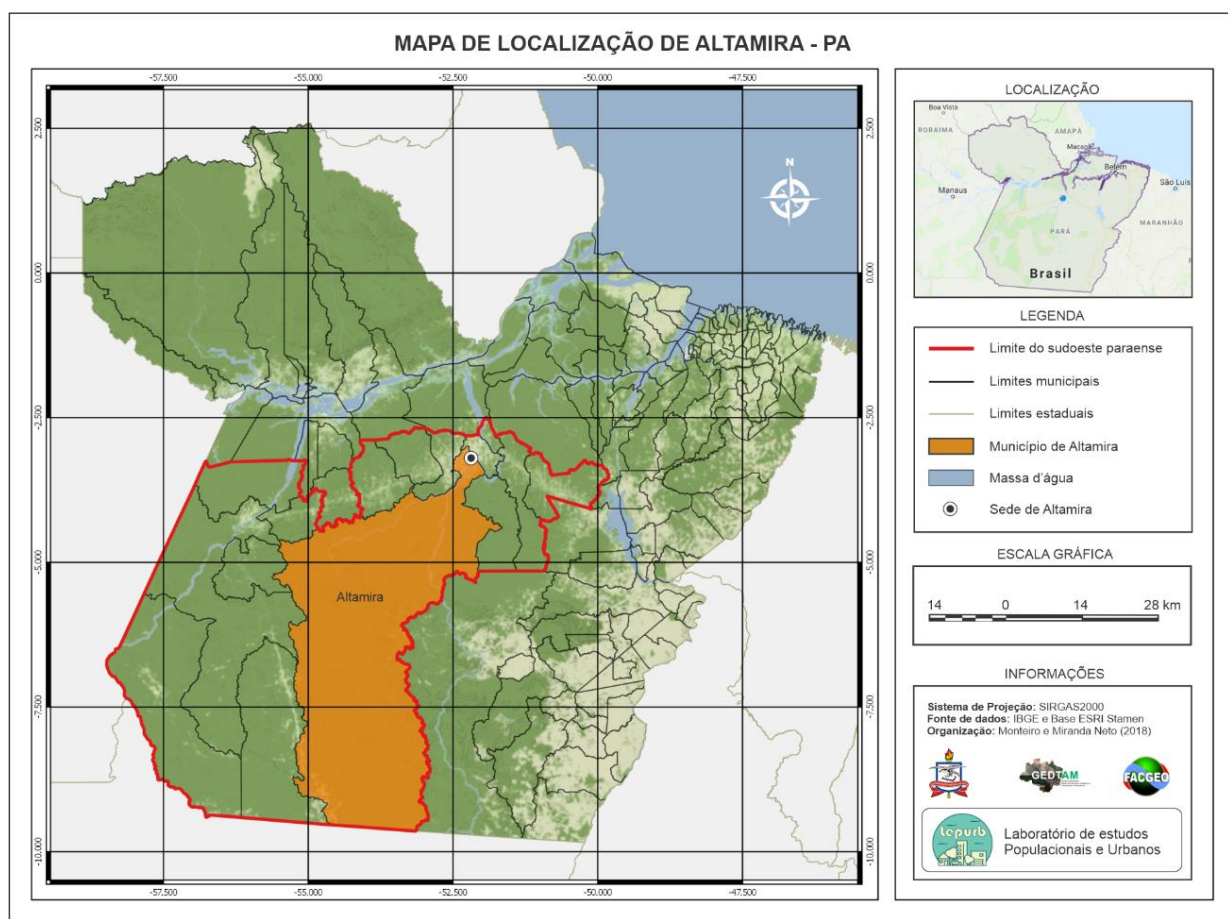

Figura 01: Mapa de Localização de Altamira

Fonte: Laboratório de Estudos Populacionais e Urbanos, disponível em: http://www.lepurb.com.br 
Compõem os objetivos dessa pesquisa descrever as principais práticas de lazer existentes na cidade de Altamira, considerando os efeitos que a UHBM trouxe à dinâmica dessas práticas e a forma com que os sujeitos da cidade passaram a se relacionar com os mesmos. O mapa da Figura 01 apresenta a localização da cidade de Altamira-PA, situada no município mais extenso do Brasil, com uma área de 159 $533,328 \mathrm{~km}^{2}$.

As estratégias de sistematização desses dados basearam-se na observação participante, nas entrevistas abertas, e em elementos da etnografia urbana presentes nos estudos de Magnani $(2002,2018)$.

Os resultados apontam para um reordenamento das práticas e dinâmicas do lazer na cidade de Altamira. Esse cenário emergente deriva da implementação da UHBM, considerada um evento, que impôs uma nova dinâmica à cidade, aos sujeitos e a (re)produção dos espaços de lazer. Tal cenário é revestido pelo surgimento de novos roteiros, trajetos, circuitos, novas interações entre sujeitos e destes com os novos e antigos espaços.

\section{Dimensões históricas do lazer}

Conforme tem defendido Mascarenhas (2005), o lazer é um fenômeno eminentemente moderno e, embora compreenda-se que historicamente a humanidade cultivou práticas que indiquem para a existência do lazer, esse trabalho problematiza essas ocorrências a partir do período conhecido como "Revolução Industrial".

Esse movimento ocorrido no continente europeu a partir do século XVIII provocou uma ruptura na forma com que a sociedade se organizava, sobretudo nos aspectos produtivos, trazendo mudanças relevantes na vida das pessoas, especialmente na forma com que estas passaram a lidar com seu tempo disponível ${ }^{2}$ (OLIVEIRA, 2004).

Parte desse reordenamento social estava ligado ao tempo de trabalho e de não trabalho, uma vez que em épocas anteriores a dita revolução não havia estabelecido uma rígida divisão do tempo. Nas sociedades pré-industriais as atividades do cotidiano, nelas incluídas as do trabalho, por vezes mesclavam-se, ocorrendo uma articulação entre os afazeres laborais e a diversão. $\mathrm{O}$ tempo de trabalho era orientado em função dos ciclos naturais, momento em que a manifestação do lazer ocorria paralelo às atividades laborais e vice-versa (THOMPSON, 1998).

Na emergência do novo paradigma produtivo e social, passaram a ser considerados basicamente dois tempos: um de trabalho e outro de descanso, este último caracterizado pelas extenuantes jornadas de trabalho a que eram submetidos os trabalhadores. O usufruto do lazer tornara-se privilégio de uma pequena parcela da população que, evidentemente, não era submetida àquela lógica degradante de trabalho.

\footnotetext{
${ }^{2}$ Marcellino (1987) considera que no sistema capitalista não é possível falar em tempo livre, daí porque sua preferência pelo termo "tempo disponível”, do qual partilhamos.
} 
Conceitualmente, Dumazedier $(1999,2004)$ caracteriza o lazer como algo ligado ao desenvolvimento humano nas suas várias dimensões, materializando-se a partir de ações realizadas no tempo disponível, fora das obrigações laborais, familiares, políticas, entre outras.

O tempo disponível é um fator determinante à prática do lazer. Logo, o desafio presente em todos os períodos históricos tem sido a forma com que os sujeitos, em especial os trabalhadores, se apropriam desse tempo para vivenciarem o lazer. De outro modo, historicamente tem havido uma negação ou uma concessão precária do tempo livre aos sujeitos que precisam reivindicar esse direito ao tempo e, consequentemente, ao lazer. Somado a isso, tem sido marcante o papel que certos setores desempenham no contexto da afirmação do lazer mercantilizado, destacando-se a indústria cultural do lazer que, de acordo com Parker (1978), sobretudo a partir do século XX, contribui para uma escalada exponencial na oferta de serviços voltados ao lazer pago.

Pelo menos nos últimos três séculos, no ocidente, as práticas de lazer disputaram espaço com a categoria trabalho, pois, conforme demonstrado, a existência do lazer pressupõe tempo disponível. Mesmo assim, convém reiterar o que afirmaram Dumazedier (2004) e Mascarenhas (2005) a respeito do lazer enquanto um "ato moderno", temporalmente marcado pelo forte processo de industrialização mencionado nesse trabalho.

A considerar as relações históricas que estiveram presentes na consecução do fenômeno lazer, é preciso pontuar algumas características relevantes. Uma delas foi a transição de um modo de vida agrário-rural para urbano-industrial (THOMPSON, 1998). Essa mudança na organização social contribuiu para que se acirrassem tensões sociais, culminado em conflitos de várias ordens. Discutindo esse período, Enguita (1989) afirma que era comum a fuga em massa de pessoas que, negando-se a submeter-se ao então modelo de produção e trabalho, fugiam de seus países. O autor ressalta que, proporcionalmente a ação desses sujeitos, existiam mecanismos de contenção como o fechamento das fronteiras, acordo entre governos e, em último caso, execução daqueles que se negavam a adequar- se ao novo modelo.

Ao relacionar o aspecto histórico entre trabalho e lazer Melo (2003), afirma que as estratégias adotadas pela classe dominante visavam tão somente conter manifestações e instaurações de ideias que trouxessem instabilidade à nova ordem econômica emergente. Esse controle se capilarizava em duas dimensões: a primeira, pelo controle da "rebeldia", pela contenção de eventuais insurgências sociais; a segunda, centrava-se no desenvolvimento do trabalho enquanto rotina propriamente dita. Esta última, baseavase na implementação de estratégias operacionais de disciplina de trabalho, como afirma:

além das preocupações com a rebeldia que grassava na sociedade, havia a necessidade de impor uma disciplina rígida de trabalho fabril, um processo mais difícil e tenso do que muitas vezes costumamos considerar. Não foi fácil adequar as camadas populares ao novo modelo de trabalho e poucos não foram os conflitos (MELO, 2003, p. 38). 
Tais medidas, direcionadas às camadas populares, deflagravam incontáveis conflitos, acirrando tensões particularmente no campo trabalhista. Essa realidade realçava as novas relações de trabalho, destacava a institucionalização do capitalismo enquanto modelo macroeconômico, ocasião em que se consolidava o controle pelo controle, acirrando a cisão entre o tempo de trabalho e o de não trabalho.

Embora compreenda-se que lazer, enquanto fenômeno, não deva ser analisado como antítese do trabalho, é importante considerar as reflexões feitas por autores como Thompson (1998) e Marcuse (2004), os quais problematizam as mudanças advindas da forma com que as relações sociais passaram a ser influenciadas por ocasião das mudanças no mundo do trabalho.

Em Marcuse (2004), a diferença essencial entre os humanos e as demais espécies é a forma com que aquela espécie lida com o trabalho, tornando o exercício laboral um elemento fundante da própria essência humana. $\mathrm{O}$ autor chama atenção para eventuais práticas entre o trabalho e a humanidade das quais podem, eventualmente, derivar relações alienantes e alienadoras. Assim, livrar a humanidade da alienação pelo trabalho, implica libertar o trabalho da alienação (MARCUSE, 2004).

O fato é que o lazer, historicamente, tem papel central na lógica de organização de qualquer sociedade, estando mais ou menos evidente a partir da forma com que as pessoas gerenciam seu tempo livre ou, nas palavras de Marcellino (1987), gozam seu tempo disponível.

Como categoria analítica o lazer passa a ser mais estudado a partir do século XX, destacando-se os estudos de Parker (1978), para quem o lazer é:

Tempo livre de trabalho e de outras obrigações, e também engloba atividades que se caracterizam por um sentimento de (relativa) liberdade. Como sucede com outros aspectos da vida e da estrutura social, o lazer é uma experiência do indivíduo, um atributo do grupo ou de outra atividade social, e possui organizações e instituições relevantes que procuram atender às necessidades de lazer, reconciliar interesses conflitantes e implementar as políticas sociais (PARKER, 1978, p. 10).

O lazer se constitui numa experiência individual ou coletiva materializada fora das obrigações laborais, fundamentado em experiências que inspirem liberdade, descanso e diversão, cuja prática dê-se de forma voluntária. Essa compreensão materializa a realidade de que sua ocorrência está circunscrita a um tempo disponível, conforme destacou Marcellino (1987) e Dumazedier (2004). Convém destacar, porém, que a existência de um tempo disponível não deve ser encarado como uma antítese do trabalho. Essa dicotomia, quase sempre subordina o lazer a uma concepção utilitarista caracterizando-o como uma compensação às jornadas de trabalho, ao fim do qual verifica-se uma relação alienada entre o trabalho e as práticas do lazer.

Essa dualidade justaposta e, ao mesmo tempo, opositiva (trabalho e lazer) tem atravessado séculos e marcado épocas pela forma com que cooperam para a organização 
das sociedades. Mascarenhas (2005) no entanto, destaca a revolução industrial como sendo o marco principal na instituição do lazer enquanto categoria de análise. Para o autor, as mudanças advindas do forte processo de industrialização ocorrido na europa exigiu dos trabalhadores e empregadores novas estratégias para, de um lado, exigir-se o direito ao lazer e, de outro, uma contraposição negativa ou concessão precária.

Esse embate, característico da época moderna, estabeleceu novos rumos ao lazer enquanto prática social e categoria de direito, uma vez que, em grande parte das nações, lazer é um direito social, a exemplo do Brasil. Do mesmo modo, essas características inauguram novos desafios e acentuam dificuldades antigas. Uma das principais tem sido a ineficiência na oferta de espaços e equipamentos públicos à população em grande parte dos espaços urbanos e rurais. Essa realiade alimenta seu pólo oposto, correspondente a uma crescente mercantilização dos espaços e equipamentos de lazer que, na lógica capitalista, ignora determinados contingentes populacionais e territoriais, a exemplo dos mais vulneráveis economicamente, em geral residentes nas periferias urbanas.

\section{As recentes transformações em Altamira e suas implicações no lazer}

De maneira geral, nas cidades brasileiras, impera uma preocupação excessivamente ligada à infraestrutura, lógica pautada numa visão homogeinizadora do espaço, tendência que relega o lazer a um caráter acessório. No ocidente, essas características homogêneas de cidades vinculam-se ao pensamento urbano, cuja matriz remonta à França do século XIX 3 .

Essa concepção urbana inaugurou um pensamento cuja lógica da cidade deveria ser representado por um espaço limpo e uniforme, em que o que não se inserisse nessa lógica deveria ser demolido, requalificado, reformado e, no caso dos sujeitos, realocados para as áreas entendidas como não nobres, afastadas do centro da cidade (VASCONCELOS; MELO, 2003).

O instituto da requalificação oculta realidades definidas a partir da lógica do capital que, operando em determinado espaço, modifica seu uso maximizando o valor de mercado a ele agregado. Essa intencionalidade modifica e cria novas relações entre pessoas, na medida em que acirrram as assimetrias socioespaciais. Daí porque tais interferências devem ser vistas com cautela, pois em geral produzem espacialidades subordinadas a lógicas externas, em que o valor de troca superpõe-se ao valor de uso. Como exemplos, pode-se citar os mega eventos no Rio de Janeiro (copa do mundo de 2014 e olimpíadas de 2016) estudado por Faulhaber e Azevedo (2015), fornecem um parâmetro do impacto das medidas requalificadoas na vida das pessoas e na organização do espaço.

\footnotetext{
${ }^{3}$ Bahia (2012 ) destaca o papel desempenhado por Georges Eugène Haussmann, administrador e político de Paris no século XIX, cuja reforma instaurada naquela capital europeia servira de modelo para outras cidades, a exemplo de Belém, coordenada por Antônio Lemos.
} 
No caso de Altamira, as últimas décadas têm reservado significativas transformações na cidade. Com a construção da UHBM, a partir de 2011, pelo menos 12 dos 19 bairros de Altamira sofreram interferências em suas estruturas físicas e demográficas, atingindo pelos menos um quarto da população quando do início da UHBM.

Para se ter uma ideia mais aproximada do impacto da UHBM na dinâmica de Altamira, a Área Diretamente Afetada Urbana (ADA URBANA), corresponde ao conjunto de 12 bairros que abrigava mais de 22 mil pessoas antes do início da obra, como se pode identificar na Tabela 01.

Tabela 01: Bairros localizados na "ADA Urbana" de Altamira-PA

\begin{tabular}{|c|c|c|c|c|c|c|c|}
\hline Bairros & $\begin{array}{l}\text { Àrea } \\
\text { total } \\
\text { (ha) }\end{array}$ & $\begin{array}{c}\text { Igarapé } \\
\text { Altamira }\end{array}$ & $\begin{array}{l}\text { Igarapé } \\
\text { Ambé }\end{array}$ & $\begin{array}{l}\text { Igarapé } \\
\text { Panelas }\end{array}$ & $\begin{array}{c}\text { Orla do } \\
\text { Xingu }\end{array}$ & $\begin{array}{l}\text { Total } \\
\text { (ha) }\end{array}$ & $\%$ \\
\hline Alberto Soares & 221,22 & 1,67 & 41,41 & & & 43,08 & 8,85 \\
\hline Aparecida & 60,86 & 10,18 & 25,47 & & & 35,65 & 7,33 \\
\hline Boa Esperança & 143,31 & & 89,23 & & & 89,23 & 18,34 \\
\hline Brasília & 67,11 & 8,65 & & & & 8,65 & 1,78 \\
\hline Centro & 107,77 & 21,52 & & & 4,98 & 26,50 & 5,45 \\
\hline Colinas & 74,27 & & 48,46 & & & 48,46 & 9,96 \\
\hline $\begin{array}{l}\text { Esplanada do } \\
\text { Xingu }\end{array}$ & 76,86 & & & & 4,06 & 4,06 & 0,83 \\
\hline Mutirão & 290,24 & & 81,29 & & & 81,29 & 16,71 \\
\hline $\begin{array}{c}\text { Jardim } \\
\text { Altamira }\end{array}$ & 207,61 & 17,86 & & & & 17,86 & 3,67 \\
\hline $\begin{array}{c}\text { Jd. } \\
\text { Independente II }\end{array}$ & 218,87 & & & 69,68 & 13,01 & 82,69 & 17,00 \\
\hline Sudam I & 44,36 & 6,93 & & & & 6,93 & 1,42 \\
\hline Sudam II & 161,41 & 42,13 & & & & 42,13 & 8,66 \\
\hline Total & 1673,89 & 108,94 & 285,86 & 69,68 & 22,05 & 486,53 & 100 \\
\hline $\begin{array}{c}\text { Total } \\
\text { Moradores }\end{array}$ & 16.420 & & & & & & \\
\hline
\end{tabular}

Fonte: Eletrobrás (2009).

A maior parte dos bairros localizava-se na confluência dos Igarapés Ambé e Altamira, onde do total de 1.673,89 hectares correspondentes ao polígono da ADA, mais de 486 ha foram afetadas diretamente. Estudos preliminares da NESA indicavam que o total de moradores residentes nesses bairros correspondia a mais de 16.000, mas pesquisas como a de Miranda Neto (2014) afirmam que esse número ultrapassa 22 mil pessoas, ou $25 \%$ do total de moradores de Altamira, números contestados por organizações sociais, a exemplo do Movimento dos Atingidos por Barragens (MAB).

Convém mencionar que tais tipologias, reducionismos de conceitos, negligenciam e invizibilizam trajetórias de vida dos sujeitos residentes nesses espaços, 
assim como reduzem um território a uma mera abreviação. Do mesmo modo, a política de preços adotada pela NESA impôs uma realidade perversa aos sujeitos residentes na ADA Urbana, que ficavam sob uma espécie de coação administrativa, momento em que coexistiam basicamete três opções: indenização, carta de crédito ou remanejamento para um dos cinco Reassentamentos Urbanos Coletivos (RUC), criados pela Norte Energia para remanejamento das famílias.

No que diz respeito às condicionantes, Corrêa (2016) afirma que as mesmas sinalizaram muito mais para ações mitigatórias e imediatistas do que para ações programáticas e duradouras, cenário que inviabilizou bandeiras mais amplas de reivindicações. Em linhas gerais, a maioria dos esforços da população diretamente afetada voltaram-se para reivindicações de ações pontuais e necessárias, como a moradia, o saneamento, a segurança, a saúde, ao passo que dimensões como o lazer ocuparam um papel de menor destaque nessas reivindicações.

Soma-se a isso o fato de ter havido, de maneira muito contudente, várias transformações na dinâmica da cidade, relacionadas sobretudo ao aumento da densidade populacional e a forte especulação imobiliária, questões urbanas diretamente ligadas aos espaços e práticas de lazer. Esse aumento demográfico, somado a outras dinâmicas relacionadas a UHBM, influenciaram diretamente na oferta e procura por espaços de lazer, tanto públicos quanto privados.

Essas mudanças coincidem com a instalação da UHBM, amplamente visualizadas pela cidade. No caso da orla da cidade, espaço de referência histórica para banhos e encontros da população, nota-se que esta lógica fora modificada pela intervenção da NESA, inaugurando uma nova espacialidade a partir da praia artificial. Em Altamira, estas praias constituíram-se condicionantes à UHBM, sendo: a praia da orla, a praia do Massanório, e a praia do Adalberto. Essa nova configuração, evidenciada pelas praias artificiais, permite-nos caracterizar as diversas formas de interações dos sujeitos com o Rio Xingu das quais derivam a fluvialidade.

Sobre a categoria fluvialidade e considerando o caso em questão, nota-se uma alteração nessa dimensão que de acordo com Oseki (2000), estão relacionadas ao modo com que as pessoas se apropriam do espaço a partir da materialidade do rio que adentra o núcleo urbano. No caso de Altamira, antes da construção da UHBM essas relações eram menos formais, não institucionalizadas,caracterizadas pela baixa mercantilização onde a relação dos sujeitos com o rio, tanto para atividades econômicas, quanto para as atividade de lazer tinha uma centralidade, cenário bem distinto atualmente.

Notadamente, esse conjunto de interação dos sujeitos com o rio e suas fluvialidades não são características privativas do momento posterior à contrução da UHBM. Tal relação tem acompanhado todo o processo constitutivo da própria história da cidade e da região. Convém destacar, no entanto, que no advento da UHBM essas relações passaram por modificações, ao mesmo tempo em que outras relações emergiram. 
Outra mudança recente em Altamira, relacionada ao lazer, diz respeito aos campos de várzea. Sobre estes, Mendes e Moreira (2011), concluiram que a especulação imobiliária contribuiu para a perda de protagonismo desses espaços, existentes em grande quantidade antes da UHBM. Uma possível dinâmica derivativa da extinção dos campos foi a instituição das "arenas" ${ }^{4 "}$ de futebol, espaço para onde migraram majoritária parcela daqueles sujeitos frequentadores dos campos de várzea.

Os campos de várzea eram organizados pelos próprios sujeitos em terrenos baldios tanto no centro, quanto na periferia da cidade. Serviam como ponto de convergência dos praticantes de futebol de diversos bairros da cidade e até de cidades vizinhas. Destacavam-se, de acordo com Mendes e Moreira (2011), os existentes nos bairros Jardim Uirapuru, Colinas, Boa Esperança e o de maior destaque: o "Poeirão", localizado no bairro Jardim Independente III. Juntos, esses e outros espaços funcionavam em rede, conectando sujeitos e territórios, ocasião em que aconteciam torneios e até campeonatos como era o caso do campeonato do "Poeirão" que reunia dezenas de atletas amadores com premiação em dinheiro, o que naturalmente acirrava as disputas intergrupos e exigia considerável logística.

A seguir, o "Poeirão" (Figura 02), localizado no bairro Jardim Independente II e que desde os anos de 1980 sediava torneios e campeonatos até hoje presentes na memória dos praticantes da modalidade esportiva em Altamira.

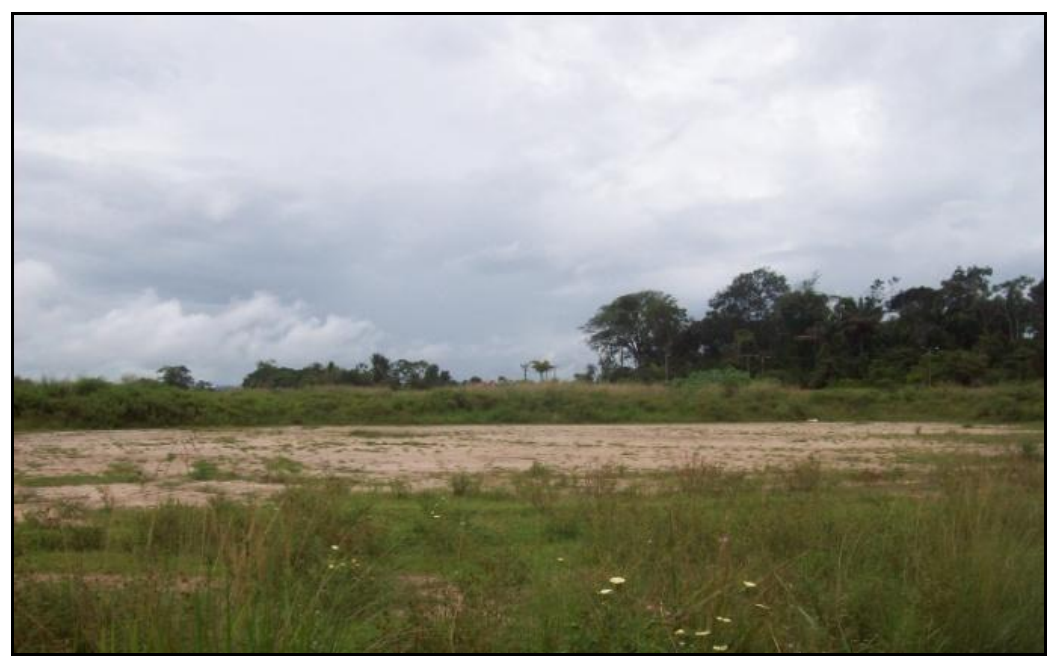

Figura 02: Campo do "Poeirão".

Fonte: Mendes (2007).

\footnotetext{
${ }^{4}$ As arenas de futebol são espaços destinados a prática do futebol com valor por hora de uso estimado em média a R\$ 50,00. Na cidade de Altamira, atualmente existem 08 delas.

${ }^{5} \mathrm{O}$ "Poeirão" era um campo de várzea localizado no bairro Jardim Independente II às proximidades do Xingu praia clube, em funcionamento desde os anos de 1980, cujo espaço já fora palco de inúmeras disputas entre times que representam os bairros da cidade.

${ }^{6}$ Atualmente o campeonato do "poeirão" é realizado nas dependências do estádio municipal.
} 
Atualmente no local do referido campo de várzea existe um condomínio residencial fechado (residencial tropical), realidade que de certa forma desfez relações historicamente mantidas com o espaço, exigindo dos sujeitos novas estratégias para vivenciarem o lazer. Uma das principas estratégias ou efeito dessa realidade foi a migração da prática realizada no campo de várzea para as arenas de futebol "society", e/ou o surgimento de campos em propriedades privadas pelo que é cobrado um determinado valor por hora jogada. Arranjos como os brevemente narrados, são derivativos dessa nova dinâmica instaurada em Altamira no pós Belo Monte.

Além das novas dinâmicas relativas às atividades físico-desportivas de lazer em Altamira, na emergência da UHBM é nítida a presença de outros roteiros e circuitos, essencialmente privados. Destacam-se estabelecimentos como bares, restaurantes e casas de festas, realçando o que se denomina nesse estudo como sendo os novos territórios do lazer que por serem privados e, de certa forma, estabelecem uma seleção social daqueles que podem menos ou mais frequentar tais espaços.

Ainda assim, mesmo diante de uma concessão precária de um direito como o lazer, ou mesmo da sua negação absoluta, é possível notar estratégias coletivas que enfretam essa realidade. Igualmente, convém destacar que tais arranjos somente são visibilizados com um olhar de perto, onde o cotidiano dos sujeitos evidencia muito dessas estratégias. Magnani (2002), ao estudar as manifestações de lazer e sociabilidade em contextos urbanos, destaca as múltiplas ações estabelecidas pelas pessoas para, mesmo diante da negação de um direito, imprimirem novas práticas.

Essas práticas se sustentam na contraposição entre o uso socialmente hegemônico de um determinado espaço e seu informal ou não hegemônico uso. No caso de Altamira, essas atividades dimensionam-se a partir dos usos atribuídos ao Rio Xingu, ao surgimento de novos roteiros como o do ramal dos cocos, o circuito de bares restaurantes, a "nova e a velha Altamira".

No caso do "Ramal dos cocos", os terrenos têm em média 30 metros de largura e 200 de comprimento limitando-se com um igarapé. O espaço tem servido tanto para residência definitiva como para sediar estrutura para receber visitas eventuais aos fins de semana. A Figura 03 apresenta a entrada do ramal pela Rod. Transamazônica, onde se tem a indicação dos balneários. 


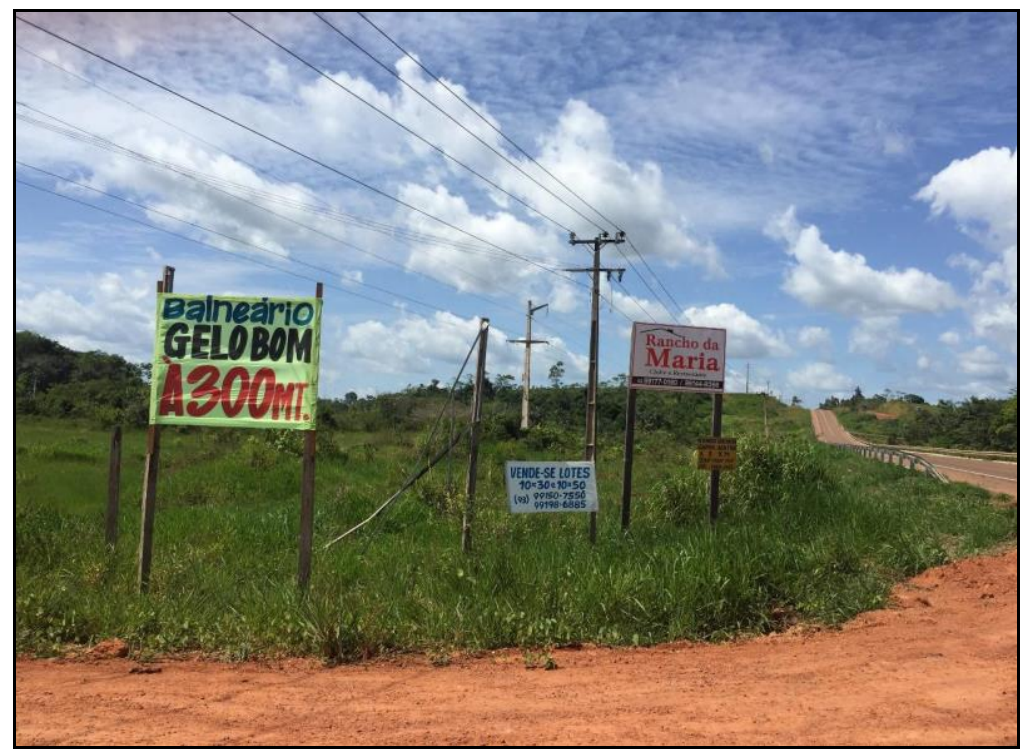

Figura 03: Acesso ao "Ramal dos Cocos" pela BR 230.

Fonte: Fotografia dos autores (2018).

Na imagem ilustrada, é possível notar a divulgação de pelo menos três espaços que funcionam como balneários. Em comum, tais espaços reafirmam o aumento de espaços e equipamentos privados na cidade e a consequente intensificação de circuitos ou roteiros de lazer. Essa exponenciação de roteiros e circuitos de lazer para além do perímetro urbano de Altamira, somada a uma escalada de oferta de espaços privados de lazer, necessariamente passa por cada vez mais uma conjunção de fatores que se fundamenta na omissão do Estado em estabelecer um conjunto de políticas públicas, ao mesmo tempo em que a iniciativa privada ocupa esse lugar a partir da mercantilização do lazer enquanto produto de consumo.

Sobre essa realidade, os estudos de Starepravo e Bernabé (2018), afirmam que tem havido uma "presença ausente" do poder público em relação às ações de lazer, paradoxo que de certa forma coopera para a manutenção e ampliação das atividades privadas do lazer. No caso de Belo Monte, ao se referir ao lazer, as previsões contidas nos documentos oficiais, como a NESA (2011), são tímidas e genéricas, resumidamente descritas: "Programa Restituição/Recuperação da Atividade de Turismo e Lazer: Projeto de Recomposição das Praias e Locais de Lazer; - Projeto de Reestruturação das Atividades Produtivas de Turismo e Lazer" (NESA, 2011). Pelo exposto, o componente do lazer seria efeito de uma ação requalificadora proposta e executada pela NESA, somado ao fato de que a materialidade do lazer vincular-se-ia à dimensão turística. Por essa descrição, o embelezamento das áreas centrais da cidade condicionaria a existência do lazer. Atualmente, essa realidade é mais claramente notada a partir dos parques e 
áreas verdes, localizados às imediações do Igarapé Altamira e da orla da cidade, como se identifica na Figura 04.

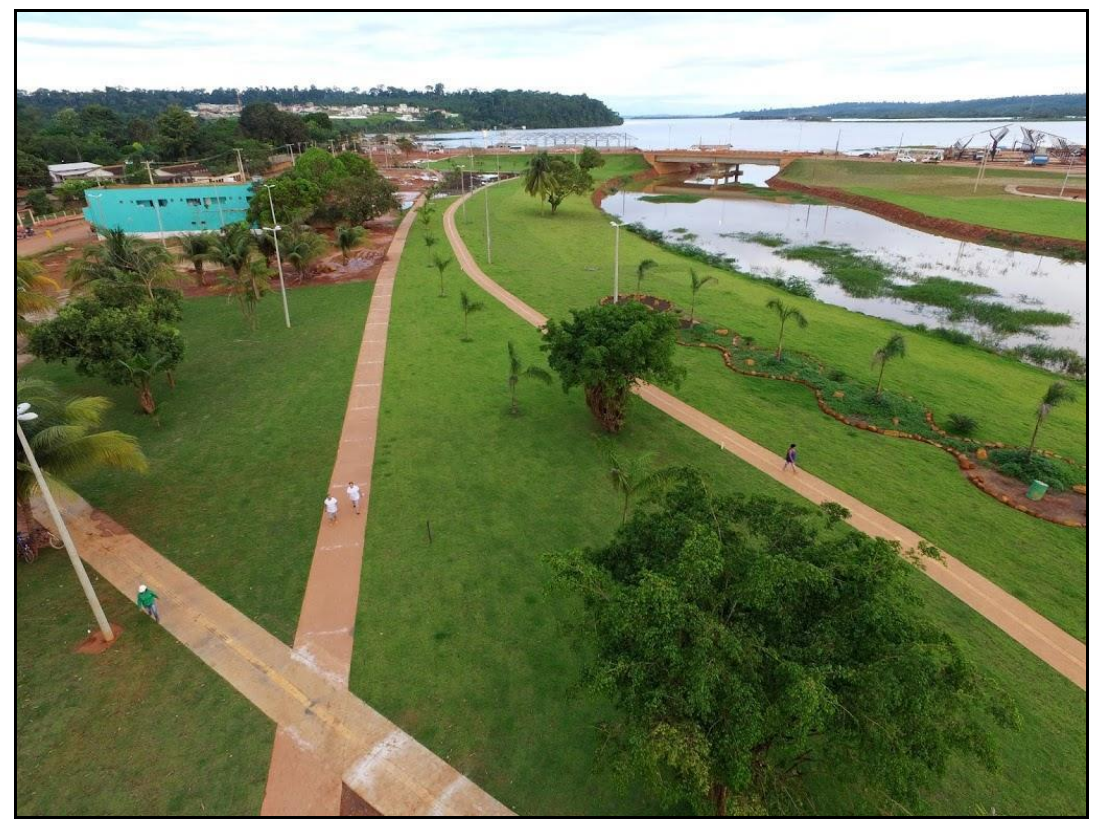

Figura 04: Parque na orla do igarapé Altamira.

Fonte: Silva (2016).

O parque acima situa-se em um dos espaços contidos na antiga ADA Urbana, próximo ao centro da cidade e às margens do Igarapé Altamira. Antes da UHBM, as duas margens eram ocupadas por um expressivo número de famílias as quais viviam em aglomerado subnormal ${ }^{7}$, sendo na rua Abel Figueiredo um local que aos domingos funcionava a Feira da Brasília $^{8}$, ponto de comércio varejista com ofertas de hortifrutigranjeiros concentrando grande número de pessoas desde as primeiras horas da manhã até o entardecer.

Atualmente, a referida rua encontra-se com condições limitadas de trafegabilidade e não concentra mais a feira. Em relação ao parque que margeia o logradouro, algumas características precisam ser problematizadas. Uma delas diz respeito a sua estrutura com raros equipamentos de lazer, outra tem a ver com a forma com que foi disposto o espaço, desconsiderando o clima quente e úmido da cidade, potencial limitador de um uso efetivo do espaço. Por fim, inexistem ações formais

\footnotetext{
${ }^{7}$ Para o IBGE: "É o conjunto constituído por 51 ou mais unidades habitacionais caracterizadas por ausência de título de propriedade e pelo menos uma das características abaixo: - irregularidade das vias de circulação e do tamanho e forma dos lotes e/ou - carência de serviços públicos essenciais (como coleta de lixo, rede de esgoto, rede de água, energia elétrica e iluminação"

${ }^{8}$ Sobre feiras em Altamira ver Guerra, Souza (2010).
} 
voltados ao lazer no local, como a existência do animador cultural, que de acordo com Melo (2003,2010) e Isayama (2009) é um profissional capaz de compreender e intervir com efetividade nas atividades do lazer para além das atividades físico-desportivas.

Ao discutirem o contexto geral das implicações trazidas pela execução da UHBM em Altamira, Herrera, Miranda Neto e Braga (2013) afirmam que ocorreu "um processo de espoliação controlado pelo capital e subsidiado por ações do Estado". Essa espoliação pode ser percebida em contextos locais e regionais, pois mesmo os estudos oficiais sinalizando que os impactos nas áreas sociais e ambientais foram em proporções menores a obras como Tucuruí, por exemplo, na prática configurou-se noutra realidade.

No que diz respeito ao conjunto de perdas vivenciandas pelos moradores da cidade, os estudos de Feitosa (2016) e Carvalho (2016) relatam os dilemas enfrentados pelos moradores da ADA Urbana quando da retirada e reassentamento dos mesmos. Em geral, o diálogo com a NESA era mínimo e as decisões quase sempre unilaterais, cabendo aos sujeitos realocados a simples concordância ou não com as "regras" impostas pela gestora. Tal clima acirrou os conflitos, desencadeando um cenário de tensão aos sujeitos envolvidos, naturalmente, mais vulneráveis no processo.

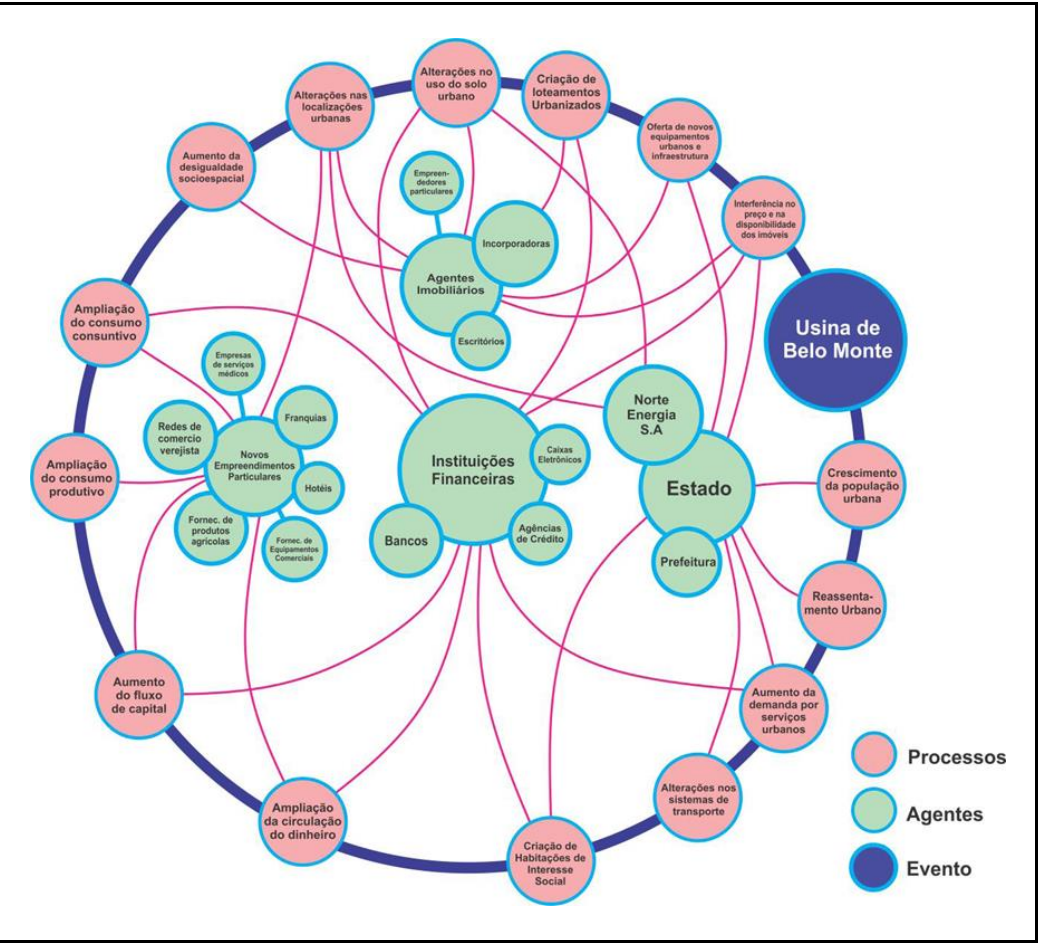

Figura 05: Reestruturação na cidade de Altamira no contexto de Belo Monte. Fonte: Miranda Neto (2016, p 177.). 
Miranda Neto (2016) afirma que em Altamira, assim como em toda a Amazônia, o modo como é pensado o desenvolvimento induz a nexos (re)estruturantes. Por essa razão, os efeitos suscitados a partir da UHBM não apenas modificam ou produzem o novo, mas também desfazem relações, geram destruições, desestruturações de laços sociais e formas do passado que, eventualmente, possam constituir barreiras à expansão do capital. A figura 04 evidencia os processos derivados do evento UHBM, dentre esses estão um conjunto de ações mediadas por agentes, instituições e pelo Estado.

Esse trabalho visou ampliar a problemática contida nesses processos considerando que o lazer enquanto categoria social é algo diretamente ligado a inserção da obra referida, uma vez que, atualmente, não se pode considerar as diversas transformações ocorridas em Altamira sem levar em conta a influência que a UHBM desempenhou nesse contrexto. Para Miranda Neto (2016 ), a UHBM é a expressão, por meio do PAC, da expansão da fronteira hidrelétrica como movimento de territorialização da dinâmica de acumulação do capital sobre a Amazônia sob forte influência do Estado, em parceria com grandes grupos privados.

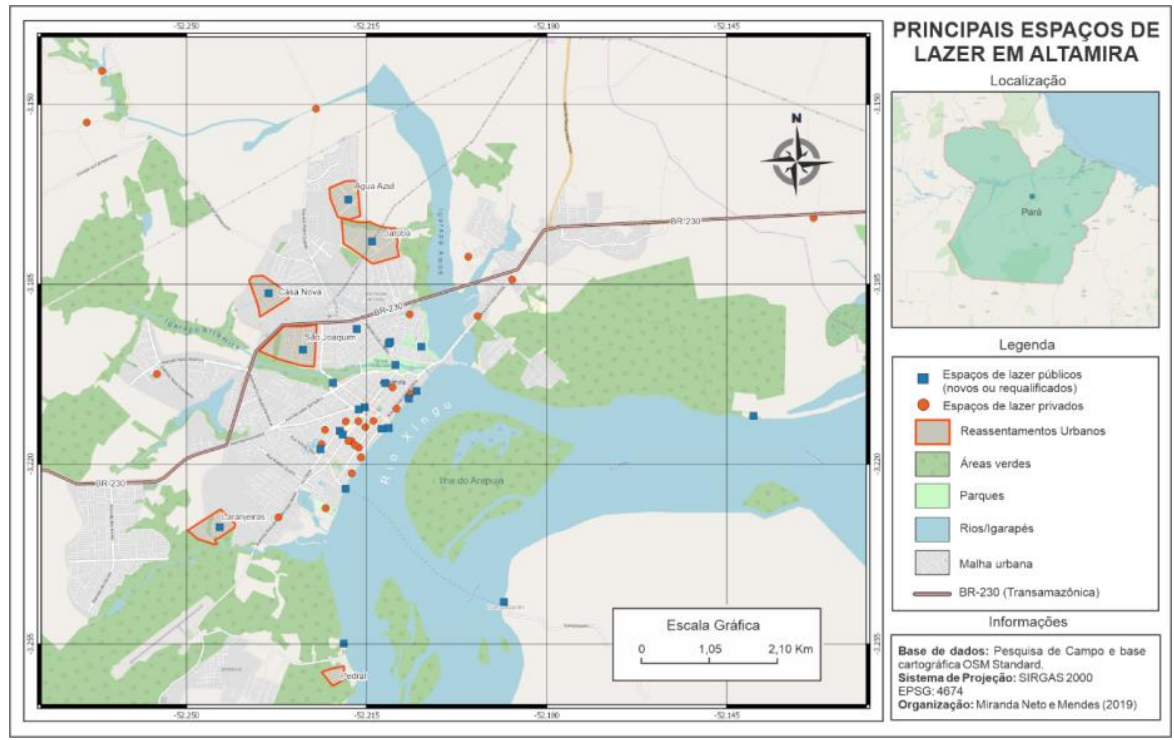

Figura 06: Principais espaços de lazer em Altamira.

Fonte: Autores (2019).

Nessa pesquisa, pode-se constatar que os espaços de lazer presentes nas imediações dos alfluentes do rio Xingu foram descaracterizados por uma proposta de requalificação contidas nos documentos oficiais. Essa proposta, a bem da verdade, visou tão somente destituir as pessoas dos seus locais de moradia, de suas relações de pertencimento e, em último caso, da suas relações de lazer historicamente mantidas com esses espaços. Do mesmo modo, o evento UHBM impôs uma nova realidade de lazer a 
toda cidade e suas população, em que novas configurações do lazer vieram a tona, caracterizada por um exponencial aumento da oferta de lazer privado, realidade que reduziu o acesso de determinados gupos sociais a determinadas práticas do lazer.

Ainda sobre essa nova realidade, nota-se uma descentralização das atividades de lazer historicamente presentes na orla da cidade para outra parte da cidade localizada mais ao centro. É característico dessa nova espacialidade a oferta de serviços a partir de bares e restaurantes, com o fato de serem todo pagos. É bem evidente essa nova espacialidade do lazer na emergência da UHBM, onde uma outra Altamira do lazer surge mais centralizada, em oposição a uma Altamira antiga, localizada às margens do rio Xingu. O Mapa da Figura 06 apresenta um aspecto dessa nova realidade.

Acrescenta-se a essa realidade o fato de que tanto nos novos bairros, quantos nos RUCS, coexistem novas dinâmicas do lazer verificados a partir do cotidiano das pessoas e do seus espaços. Emergem, em contraposição a essa escalada de espacos e atividades privadas de lazer, circuitos, roteiros, conforme afirma Magnani (2002) ao se referir a novas estratégias coletivas para vivenciarem o lazer. Compõe esses conjunnto de atividades a relação que os sujeitos tem com determinados espaços, como é o ramal dos cocos, estrada da serrrinha, estrada da princesa do xingu, todos espaços para além do limite urbano de Altamira, mas que se constituem como indutor de várias práticas de lazer, sobretudo, relacionadas a forma de interação dos sujeitos como os igarapés.

\section{Considerações finais}

O lazer enquanto categoria de direito e fundamentalmente como expressão cotidiana das práticas sociais se reveste de uma singular relevância na estrutura social. Sua ocorrência possibilita o desenvolvimento humano, tanto no aspecto individual, quanto no coletivo.

Todavia, historicamente tem havido um certo negligenciamento dessa categoria, caracterizado por um espécie de disputa entre uma concepção hegemônica e outra informal. Esta última manifesta-se nas brechas da cidades, nas manchas e nos pedaços de território interdependentes na cidade.

Na Amazônia, o lazer ainda padece de históricos desafios, representado em grande parte por uma concessão precária ou mesmo uma invisibilidade de suas práticas enquanto um direito social. Em Altamira, tem-se alguns agravantes, representados em grande medida por uma histórica vinculação da cidade à implementação de grandes projetos, sempre pensados numa lógica exógena.

Essa caracterização a partir de grandes projetos, a exemplo da UHBM, impoem relevantes desafios à cidade e acirra antigos problemas, como é o caso do acesso aos espaços e equipamentos de lazer. Ainda assim, pode se notar duas realidades distintas: a primeira representada por uma institucionalidade dos espaços e equipamentos de lazer, as quais sugerem um uso hegemônico desses espaços; a segunda é caracterizada por uma 
perspectiva que centraliza as práticas do lazer a partir da vivência dos sujeitos, priorizando usos não hegemônicos dos espaços.

No caso de Altamira, na emergência de mais um grande projeto como a UHBM, o que se percebe é a institucionalização de uma nova dinâmica no campo do lazer. Essa realidade é manifestada pelas novas formas com que os sujeitos interagem com os espaços, produzindo novas espacialidades. A outra face dessa dinâmica tem a ver com a forma com a qual os entes e determimados agentes agem, produzindo igualmente modificações na estrutura do lazer na cidade.

Essa configruação, em certa medida antagônica, mas de certo modo complementar, induz a uma nova dinâmica do lazer em Altamira a que nos referimos da qual derivam variadas práticas protagonizadas pelos sujeitos em suas relações cotidianas.

Ainda que se considere que as provocações feitas ao longo desse trabalho não encerrem o debate sobre o lazer em Altamira, o que se almeja, sobretudo, é inserir as cidades médias da Amazônia no debate do lazer, considerando o impacto que a implementação de grandes obras, a exemplo de hidrelétricas, provocam neste campo.

Desse modo, espera-se que este trabalho suscite, em conjunto com outras pesquisas realizadas na Amazônia, a discussão a respeito da visibilidade das práticas de lazer presentes nesse território, que certamente indicam caminhos plausíveis para que se tenha cidades e regiões cada vez mais democráticas para o lazer.

\section{Referências}

Bahia, M. C. O Lazer e as relações socioambientais em Belém - Pará. Tese (Doutorado)- Universidade Federal do Pará, Núcleo de Altos Estudos Amazônicos, Programa de Pós-Graduação em Desenvolvimento Sustentável do Trópico Úmido, Belém, 2012.

CARVALHO, G. B. Os novos espaços de assentamento e a representação urbana em Altamira-Pará: uma análise dos reassentamentos urbanos coletivos. 21f.Trabalho de Conclusão de Curso (Graduação) - Universidade Federal do Pará, Altamira, 2016

CORRÊA, S. R. M. Neodesenvolvimentismo e conflitos sociais: o caso da Hidrelétrica de Belo Monte. Novos Cadernos NAEA, v. 19, n. 3, p. 233-254, set-dez 2016.

DUMAZEDIER, J. Sociologia empírica do Lazer. [Tradução: Silvia Mazza e J. Guinsburg]. São Paulo: Perspectiva, 1999.

DUMAZEDIER, J. Lazer e cultura popular. $3^{\mathrm{a}}$ ed. São Paulo: Ed. Perspectiva, 2004.

ELETROBRÁS. Estudo de impacto ambiental-EIA, Relatório de impacto ambiental da Usina Hidrelétrica de Belo Monte-RIMA, Belo Monte. Brasília, 2009

ENGUITA, M. F. A face oculta da escola: a educação e o trabalho no capitalismo. Porto Alegre: Artes Médicas sul, 1989. 
FAULHABER, L., AZEVEDO, L. Remoções no Rio de Janeiro olímpico. Rio de Janeiro: Mórula, 2015.

FEITOSA, B. H. O processo de reassentamento das famílias do antigo bairro Açaizal "centro" a partir do empreendimento hidrelétrico de Belo Monte em Altamira-Pará. 22f.Trabalho de Conclusão de Curso (Graduação) - Universidade Federal do Pará, Altamira, 2016

HERRERA, J. A., MIRANDA NETO, J. Q. de, MOREIRA R. P. Integração e estruturação do território Amazônico como consequência da expansão capitalista no Brasil. Bol. geogr., Maringá, v. 31, n. 2, p. 19-36, maio-ago., 2013

IBGE. Instituto Brasileiro de Geografia e Estatística. Divisão urbano-regional: procedimentos operacionais. Rio de Janeiro, 2017.

ISAYAMA, H. F. Atuação do Profissional de Educação Física no âmbito do Lazer: a Perspectiva da Animação Cultural. Motriz, Rio Claro, v.15, n.2, p.407- 413, abr./jun. 2009

MAGNANI, J. G. De perto e de dentro: notas para uma etnografia urbana. Revista Brasileira de Ciências Sociais, vol. 17, n. 49. p. 1-34. São Paulo, junho de 2002.

MAGNANI, J. G. Do mito de origem aos arranjos desestabilizadores: notas introdutórias. In: Magnani, José Guilherme Cantor; Spaggiari, Enrico (orgs) Lazer de perto e de dentro: uma abordagem antropológica. São Paulo: Edições Sesc São Paulo, 2018.

MARCELLINO, N. C. Lazer e educação. Campinas: Papirus, 1987.

MARCUSE, H. Razão e revolução: Hegel e o advento da teoria social. São Paulo: Paz e Terra, 2004.

MASCARENHAS, F. Entre o ócio e o negócio: teses acerca da anatomia do lazer. 2005. Tese (Doutorado em Educação Física) - Faculdade de Educação Física, Universidade Estadual de Campinas, Campinas, 2005.

MELO, V. A. de. A formação cultural do animador cultural: antigas reflexões, persistências, continuidades. In: ISAYAMA, H. F. (Org.) Lazer em estudo: currículo e formação profissional. Campinas: Papirus, 2010, p. 127-142.

MELO, V. A. de. Lazer e minorias sociais. São Paulo: Ibrasa, 2003. MELO, 2003, p

MENDES, F. J. da C. Arquivo pessoal, 2007.

MENDES, F. J. da C.; MOREIRA, L. K. R. Espaços e equipamentos de lazer na cidade de Altamira/PA.73f.Trabalho de Conclusão de Curso (Graduação) - Universidade do Estado do Pará, Altamira, 2011.

MIRANDA NETO, J. Q. de. Reassentamento da população urbana diretamente afetada pelo empreendimento hidrelétrico de belo monte em altamira- pa. Revista Nacional de Gerenciamento de Cidades, v. 02, n. 13, p. 43-57, 2014. 
MIRANDA NETO, J. Q. de. Os nexos de re-estruturação da cidade e da rede urbana: o papel da Usina Belo Monte nas transformações espaciais de Altamira-PA e em sua região de influência. Tese (Doutorado em Geografia) -Faculdade de Ciência e Tecnologia da Universidade Estadual Paulista- Presidente Prudente - São Paulo, 2016.

NORTE ENERGIA S.A. Plano Básico Ambiental da Usina Hidrelétrica de Belo Monte. 2011.

OLIVEIRA, E. M. Transformações no mundo do trabalho, da revolução industrial aos nossos dias. Caminhos de Geografia v.6, n.11, p. 84-96, Fev/2004.

OSEKI, J. H. A Fluvialidade no Rio Pinheiros: Um Projeto de Estudo. Revista do Programa de Arquitetura e Urbanismo da FAU-USP, São Paulo, 2000.

PARKER, S. A sociologia do lazer. Rio de Janeiro: ed. Zahar Editores, 1978.

SILVA, B. Usina Hidrelétrica de Belo, Rio Xingu Pará. 2016. Disponível em: https://www.skyscrapercity.com/showthread.php?t=1059695\&page=62. Acesso em: $15 / 02 / 2018$.

SOUZA, C. A. M. de; GUERRA, G. A. D. Feiras em Altamira, Pará: confluência de universos de significação. Relatório de Pesquisa, amazônica, ano 2, v.1, p. 140-160, 2010

STAREPRAVO, F. A., BERNABÉ, A. P. Lazer e políticas públicas no século XXI. In Lazer e esporte no século XXI: novidades no horizonte? MOREIRAA, W. W.; SILVA, J. V. P. da. Curitiba: interSaberes, 2018.

THOMPSON, E. P. Costumes em comum. Trad. Rosaura Eichemberg. São Paulo:Companhia das Letras, 1998.

UMBUZEIRO. A. U. B.; UMBUZEIRO, U. M. Altamira e sua história. 4ed. Belém, Ponto Press, 2012.

VASCONCELLOS, L. M.de; MELLO, M. C. F. de. Terminologias em busca de uma identidade. Revista Rua, Salvador, ano 4 v.1, n.8, p. 60-66, jul./dez.2003.

Francivaldo José da Conceição Mendes

Licenciado em Educacão Física, Técnico em Assuntos Educacionais na Universidade Federal do Pará- UFPA-Campus de Altamira. Doutorando em Geografia do Programa de Pós-Graduação em Geografia-PPGEO/UFPA.

Rua Augusto Corrêa, 01 - Guamá. Cep 66075-110. Belém, Pará, Brasil.

e-mail: francivaldo.edfisica@gmail.com

César Augusto Martins de Sousa

Licenciado em História, Doutor em História e Professor da Universidade Federal do Pará (UFPA - Campus de Bragança), e do Programa de Pós-Graduação em Linguagens e Saberes na Amazônia- PPLSA.

Alameda Leandro Ribeiro - Aldeia, Bragança - PA, 68600-000. 
Lazer em Altamira-PA e as tranformações após a construção da Usina Hidrelétrica...

\section{José Queiroz de Miranda Neto}

Licenciado em Geografia, Doutor em Geografia e Professor da Universidade Federal do Pará (UFPA - Campus de Altamira), e do Programa de Pós-Graduação em Geografia- PPGEO/UFPA.

Rua Cel. José Porfírio, 030 - Recreio, Altamira - PA.

E-mail: geoneto@msn.com

Recebido para publicação em janeiro de 2020 Aprovado para publicação em março de 2020 